\section{Switch to ecological engineering would aid independence}

SIR - In your News Feature 'Is China ready for GM rice?' (Nature 455, 850-852; 2008), you consider the merits of using genetically modified (GM) crops for pest control. But don't overlook the potential of ecological engineering, which can provide an important and undervalued approach to tackling agricultural problems.

Biological control in irrigated rice is a prime example of how increasing biodiversity can offer a key service to humans. Insect pests in rice are efficiently controlled by appropriate reduction of pesticide application together with landscape management (see, for example, M. J. Way and K. L. Heong Bull. Ent. Res. 84, 567-587; 1994). This strategy has led to almost complete abolition of insecticide application in places such as the research fields of the International Rice Research Institute (IRRI) in the Philippines.

It was the strikingly successful example of biodiversity and ecosystem services management by IRRI that persuaded us to recruit the institute into a large international research network (J. Settele et al. Nature 453, 850; 2008), with a view to developing sustainable land use on a global scale and refining ecologicalengineering approaches.

Employing GM rice for pest control overlooks services available from natural resources that are not so dependent on big business and so do not undermine the independence of farmers and developing nations. Switching investment of resources from GM crops and pesticides to ecological engineering could be a more efficient long-term and low-cost strategy.

In such a well-studied crop as rice, ecological engineering could be implemented immediately. Research efforts should focus on developing sustainable management schemes for ecosystem services for other key crops, in China and worldwide.

Josef Settele UFZ, Helmholtz Centre for Environmental Research, Theodor-Lieser-Strasse 4, 06120 Halle, Germany e-mail: Josef.Settele@ufz.de Jacobus Biesmeijer Institute of Integrative and Comparative Biology and Earth and Biosphere Institute, University of Leeds, Leeds LS2 9JT, UK Riccardo Bommarco Department of Ecology, Swedish University of Agricultural Sciences,

75007 Uppsala, Sweden

\section{Offering unproven genetic tests to the public is irresponsible}

SIR - Your News story

'Alzheimer's tests under fire'

(Nature 455, 1155; 2008)

highlights the fierce debate about the availability of genetic tests to the general public. The overwhelming amount of data concerning the major genetic risk factors for Alzheimer's disease have recently been summarized: they show that various markers, although promising, are far from conclusive and are much farther from mainstream use than the controversial APOE test (L. Bertram and R. E. Tanzi Nature Rev. Neurosci. 9, 768-778; 2008), whose flaws you describe.

During our 15 years of studying genetic risk factors for Alzheimer's disease (see J. R. M. Oliveira et al. J. Mol. Neurosci. doi 10.1007/s12031008-9124-0; 2008), our group has often been approached by private laboratories and colleagues interested in making APOE genotyping - and many other markers - available to the general public.

In our experience, non-affected family members are often interested in knowing their genotype, in the hope of preventing the disorder. But laypeople are rarely well equipped to understand the often murky relationship between their genotype and phenotype. They may reach erroneous conclusions, make irresponsible lifestyle decisions or pursue unproven therapies if their test results seem alarming.

The core of the problem is a misunderstanding of crucial terms such as risk factor, prevention, cure and treatment, along with the false notion that medication is available to prevent the manifestation of symptoms. People who become aware of their genetic risk factors through a test with limited predictive power will be forced to grapple with a complex set of uncertainties. That is not a responsible way to offer medical information.

\section{J. R. M. Oliveira Neuropsychiatry} Department and Keizo Asami Laboratory, Federal University of Pernambuco, Recife-PE 50670-901, Brazil

\section{Speaking up for economic-sciences modelling}

SIR — In his Essay 'Economics needs a scientific revolution' (Nature 455, 1181; 2008), Jean-Philippe Bouchaud cites the Moon landings as a remarkable achievement of physics and asks, rhetorically, what economics can offer as its flagship achievement. I submit that a society prosperous enough to pay for Moon landings is one such achievement.

In both cases, this was applied science (engineering and economic policy, rather than physics or economics perse), but previous research was crucial for making those applications possible. More recent NASA disasters and financial crises are signs that the existing science is not always applied - not that the existing science is useless.

Just like physicists (Bouchaud's comparison group), economists are happy to use simple models when these will serve. But those simple models are not all that there is to either subject.

This year's Sveriges Riksbank Prize in Economic Sciences in Memory of Alfred Nobel was awarded to Paul Krugman for his research on how imperfect competition affects trade and the location of economic activity. Other recent laureates have done research on behavioural economics (which Bouchaud calls a "fringe endeavour ... not taken seriously by mainstream economics"), on policy design when markets are inefficient, and on the behaviour of imperfectly informed economic agents. Contrary to Bouchaud's implication, the models of the 1950s do not mark today's research frontier in economics, any more than they do in physics.

The current economic crisis is a result of reckless behaviour by financial corporations and of the poor financial regulation that could not contain it. Let us remember, however, that the worst-case outcome is that average incomes in some countries might drop to levels last seen in the 1990s - when those same incomes were the highest ever experienced - and that unemployment might temporarily rise to $10 \%$ or $12 \%$, which our grandparents would have considered unremarkable. The fact that we now see such a potential outcome as disastrous (as indeed we should) is a sign of the success of economics, not of its failure.

Jesper Stage Department of Economics, University of Gothenburg PO Box 640, 40530 Gothenburg, Sweden e-mail: Jesper.Stage@economics.gu.se

Readers are welcome to comment at $h$ ttp://tinyurl.com/6y5ny3 or at http://tinyurl.com/6gjg86.

\footnotetext{
Contributions to this page may be submitted to correspondence @nature.com. Please see the Guide to Authors at http:// tinyurl.com/373jsv. Published contributions are edited.
} 